\title{
Impact assessment of plant protection technologies validated/ demonstrated by KVK, Angul (Odisha) during 2002-2009
}

\author{
NIRANJAN DAS* AND R.P. MISHRA
}

Krishi Vigyan Kendra, BOUDH (ODISHA) INDIA

\section{ARITCLE INFO}

Received : 13.06 .2015

Accepted : 15.03 .2016

\section{KEY WORDS :}

Impact, Assessment, Plant protection technology
*Corresponding author:

Email: ndasouat@yahoo.co.in

\begin{abstract}
A good number of agro technologies have been assessed and demonstrated in the farmers' field by KVK, Angul during 2002-2009. Impactassessment of plant protection technologies revealed that the technologies are being adopted by the farmers at variable rate over time. Highest adoption rate $(65 \%)$ was observed with application of Acephate 75 per cent SC twice @ 0.2 per cent at 15 days interval for management of aphid in mustard with horizontal expansion to 382 ha area. On the other hand lower adoption rate $(6 \%)$ was observed for the technology of release of bio-agent Chrysoperla cornea for management of this insect pest. The IPM technology consisting of removal of affected fruits and shoots followed by alternate spraying of Triazophos@ 0.2 per cent and neem oil @ 0.5 per cent with teepol at 15 days interval for management of shoot and fruit borer was found to be adopted by 52 per cent participants with horizontal spread to 264 ha of additional area. Non-availability of inputs and seeds of high yielding variety of crops, delay in input availability, non-availability of resistant variety, inadequate supply of inputs and poor quality of inputs, non-availability of skilled labours ,high cost of labour and lack of credit facility are the major constraints for low adoption of these technologies. These constraints need to be addressed systematically to improve the adoption percentage of these technologies.
\end{abstract}

How to view point the article : Das, Niranjan and Mishra, R.P. (2016). Impact assessment of plant protection technologies validated/demonstrated by KVK, Angul (Odisha) during 20022009. Internat. J. Plant Protec., 9(1) : 252-255. 